\begin{tabular}{|c|c|c|}
\hline 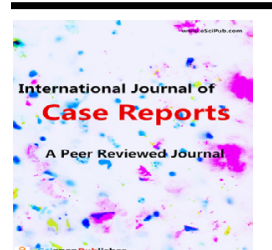 & $\begin{array}{l}\text { International Journal of Case Reports } \\
\text { (ISSN:2572-8776) }\end{array}$ & 品 \\
\hline
\end{tabular}

\title{
Phosphate Enema Causing Life-Threatening Rectal Perforation
}

\author{
N. Bobb, V. Naraynsingh, S. Islam, Y. Singh, D. Harnanan, S. Cawich
}

Department of Clinical Surgical Sciences The University of the West Indies, Eric Williams Medical Sciences Complex, Mount Hope, Trinidad, West Indies.

\section{ABSTRACT}

We report a near fatal rectal perforation due to a phosphate enema in an elderly male. The presentation in septic shock within 4

*Correspondence to Author:

hours of the enema is quite rare. Early recognition and prompt V. Naraynsingh

management are essential for a good outcome. A defunctioning

Department of Clinical Surgical Scicolostomy is standard for these cases but we recommend a disences The University of the West tal rectal washout since intraluminal faeces in a loaded rectum could be a cause of ongoing sepsis. Although enemas are comIndies, Eric Williams Medical Sciences Complex, Mount Hope, Trinimonly used for constipation in the elderly, suppositories and oral preparations should be used preferentially where appropriate.

Keywords: Enema, Rectal Perforation, Septic Shock

How to cite this article:

N. Bobb, V. Naraynsingh, S. Islam, Y. Singh, D. Harnanan, S. Cawich. Phosphate Enema Causing Life-Threatening Rectal Perforation. International Journal of Case Reports, 2020 4:167.

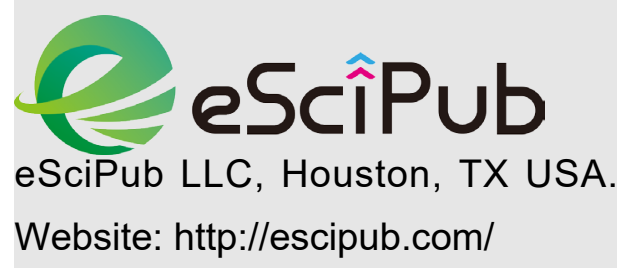




\section{Introduction}

Rectal enemas are readily given to the elderly by care givers, most frequently for the treatment of chronic constipation. Although complications following administration of enemas are uncommon, they can be quite dangerous. We report the case of a near fatal rectal perforation in an elderly male secondary to phosphate enema administration, and discuss the management this complication.

\section{Case}

A 75 year-old male who was scheduled for a prostate biopsy the following morning was administered a Fleet ${ }^{\circledR}$ (sodium biphosphate and sodium phosphate) enema by his relative. Approximately 4 hours after receiving the enema, he presented to the emergency department complaining of moderate pelvic pain. He was toxic, disoriented, groggy, with cold, clammy extremities and a thready pulse. His abdomen was soft and non-tender. His vital signs were blood pressure $80 / 50 \mathrm{mmHg}$, pulse 96 , respiratory rate
24 and temperature 36 degrees Celsius. A digital rectal examination revealed a small amount of bright red blood in the rectum and crepitus along the distal left rectal wall. A computed tomography (CT) scan of his abdomen demonstrated multiple tiny locules of air densities within the middle and lower posterior mesorectal fat on the left with diffuse presacral fat stranding suggestive of anorectal perforation [Figure 1].

Because of septic shock, and his instability and the absence of peritonitis no exploratory laparotomy was done. A trephine loop sigmoid colostomy was created [Figure 2]. Utilizing the caudal loop, the distal sigmoid and rectum were irrigated with warm saline until clear. In the ICU, he remained hypertensive and oliguric over the next 24 hours. On the second day post-op, his BP and urine output improved and returned to normal on the third day.

He was discharged after 7 days and his loop colostomy reversed at 3 months after a normal colonoscopy.

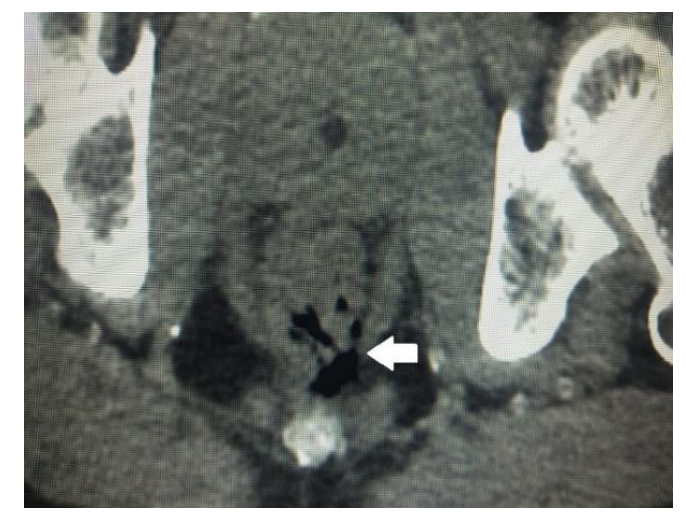

Figure 1 Axial CT image of the pelvis showing locules of free air (white arrow)

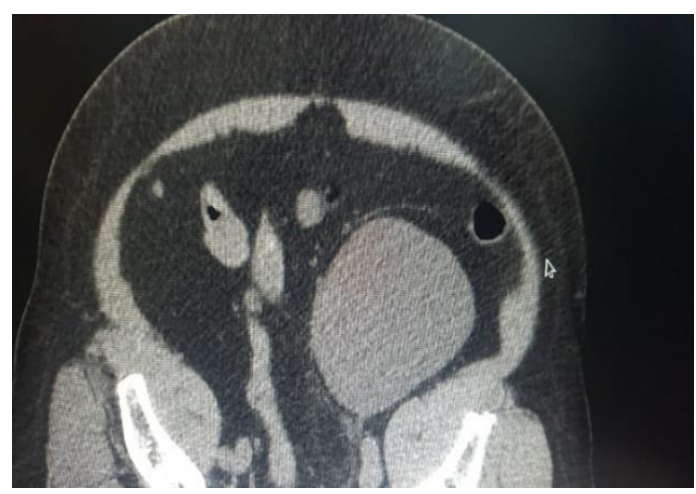

Figure 2 A large left renal cyst displaced the sigmoid colon (arrow) anteriorly facilitating the trephine colostomy. 


\section{Discussion}

The practice of administering fluids rectally can be dated back to Egypt in ancient times. In the fifteenth and sixteenth centuries a precursor to the modern enema consisting of tubes and then metal syringes to introduce weak salt solutions into the rectum was developed ${ }^{[1]}$. In the seventeenth century rectal enemas were performed more commonly; in France and Holland, it was illegal for an enema to be administered by anyone except a doctor ${ }^{2,3}$. However, by the $19^{\text {th }}$ century rectal enemas for colonic lavage using oils became popular across Europe and North America ${ }^{[1]}$.

In modern day, rectal enemas are used for many reasons and their administration is no longer restricted only to doctors. The most common therapeutic use is the treatment of constipation in the elderly ${ }^{[4]}$. Rectal enemas are now manufactured in disposable plastic bottles with short tips to reduce trauma during administration. However, enemas may cause major complications from rectal perforation.

These patients usually become symptomatic in the first 24 hours ${ }^{[5]}$. Symptoms can range from mild pelvic pain to fulminant septic shock. Rectal bleeding is highly suspicious of rectal injury in patients who have had a recent enema ${ }^{[6-10]}$. Its presence mandates rectal examination; a mucosal tear with underlying crepitus is also suggestive of rectal necrosis ${ }^{[11]}$. Our patient presented with septic shock within 4 hours of enema administration and had the classical features of blood on rectal examination and crepitus in the rectal wall.

Several case reports have described rectal perforation subsequent to enema administration ${ }^{[6-}$ 8,12-14]. These perforations are more common in the extraperitoneal rectum, below the anterior peritoneal reflection ${ }^{[12]}$. The injury is usually located above the dentate line, and therefore can be painless until the inflammatory reaction from the hypertonic phosphate solution ensues. However, septic complications and in particular, septic shock can present within hours as seen in our case. This life threatening complication needs early recognition and prompt management. More commonly, a severe chemical reaction may result in necrosis of perianal tissues including the anal sphincters ${ }^{[6,14]}$. The initial surgery following resuscitation of the patient in the majority of the reported cases was a diverting colostomy [6,7]. However, many of these patients with tissue necrosis had poor outcomes. Serial debridements of necrotic perirectal tissue were required; one patient had an abdominoperineal resection because of extensive necrosis of the perineum ${ }^{[6]}$. The postoperative course of several patients was also complicated by recurrent perineal abscesses and fistulae.

The value of distal rectal washouts is controversial. Shannon et al reviewed 26 patients with extraperitoneal rectal injuries secondary to gunshots, stab wounds and pelvic fractures. The patients who had proximal colostomy and washout of the distal rectosigmoid were compared to those who had proximal colostomy without washout. The patients who had distal rectal washouts had a decreased incidence of pelvic abscess (8 vs $46 \%$ ), rectal fistulae (8 vs $23 \%$ ) and sepsis (8 vs $15 \%)^{[16]}$.

In contrast, Burch et al did not demonstrate any significant difference in infectious complications in patients with similar injuries in their case series [17]. Similarly, a systematic review in 2016 concluded a perioperative distal rectal washout for extraperitoneal rectal injuries does not decrease infectious complications. However, it has been suggested that distal irrigation be used in patients with rectal injuries caused by high-velocity missiles which are associated with significant soft tissue injury and residual fragments ${ }^{[18]}$. There are no comparable large case series in the literature, of rectal perforations secondary to enemas. Additionally, the mechanism of injury with enemas is mechanical, chemical and septic; therefore, the above studies may not be applicable to this unique combination. Our patient did exceedingly well compared to other cases in the literature after undergoing a distal rectal washout in addition to a diverting colostomy. The washout appeared particularly important since 
he was presenting with complications of severe sepsis, and had much faeces distal to the colostomy.

Although chemical injury from phosphate enema may be unaffected by distal washout (since the washout is intraluminal and the chemical injury is extraluminal), the washout may be valuable in decreasing septic complications [16]. Although serious complications such rectal perforation following phosphate enemas are not common, we should reassess its indications and use [9,19]. Other products besides enemas such as suppositories and oral paraffin oil also relieve constipation and should be considered in preference over phosphate enemas, especially in the elderly. Furthermore, rectal enemas should not be given in the presence of rectal mucosal trauma, inflammatory bowel disease, advanced rectal cancer or recent radiotherapy to the pelvis ${ }^{[5]}$.

\section{Conclusion}

Administration of a rectal phosphate enema is not an innocuous procedure. Low rectal injury can occur from trauma secondary to the nozzle with sepsis and chemical insult from the hypertonic solution can cause extensive tissue necrosis. Many reports have documented poor outcomes in similar cases. We believe that, in addition to a diverting loop colostomy, a distal rectal washout is an important treatment step to minimize sepsis.

\section{References}

[1]. Doyle D. Per rectum: a history of enemata. J R Coll Physicians Edinb. 2005;35:367-370.

[2]. Sonnedicher G. Kremner's and Urdang's History of Pharmacy. JB Lippincott; 1951. Philadelphia: JB Lippincott; 1949.

[3]. Gijwilt-Hofstra M, van Heteren G, Tansey E. Biographies of Remedies: Dutch and American Healing Cultures. New York: Rodopi; 2002.

[4]. Mendoza J, Legido J, Rubio S, Gisbert J. Systematic review: the adverse effects of sodium phosphate enema. Alimentary Pharmacology \& Therapeutics. 2007;26(1):9-20.

[5]. Bowers B. Evaluating the evidence for administering phosphate enemas. British Journal of Nursing. 2006;15(7):378-381.
[6]. Pietsch J, Shizgal H, Meakins J. Injury by hypertonic phosphate enema. CMA Journal. 1977;116:1169-1170.

[7]. Smith I, Carr N, Corrado O, Young A. Rectal Necrosis after a Phosphate Enema. Age and Ageing. 1987;16(5):328-330.

[8]. Blatt L. Injury of the Rectum by Tip of Disposable Enema. AMA Archives of Surgery. 1960;80(3):442.

[9]. Thiele J, Zander J. Enema-Induced Anorectal Injuries Trusting the warning signs is key to prevention and treatment Enema administration is not devoid of risk for the patient. In this article, the authors highlight two cases of anorectal injury and discuss the steps critical to successful therapy, including recognition of damage. Postgraduate Medicine. 2002;111(1).

[10]. Sweeney J, Hewett P, Riddell P, Hoffmann D. Rectal gangrene: a complication of phosphate enema. Medical Journal of Australia. 1986;144(7):374-375.

[11]. Addison R, Ness W, Abulafi M, Swift I. How to administer enemas and suppositories. Nurs Times. 2000;96(6):3-4.

[12]. Wolfe W, Silver D. Rectal perforation with profuse bleeding following an enema. Arch Surg. 1966;92:715.

[13]. Bell A. Colonic Perforation with a Phosphate Enema. Journal of the Royal Society of Medicine. 1990;83(1):54-55.

[14]. Samadian S. Rectal necrosis due to phosphate enema. Care of the Elderly. 1990;2(7):291.

[15]. Judd E, Pollock L. Diverticulitis of the colon. Ann Surg. 1924;80(3):425-438.

[16]. Shannon F, Moore E, Moore F, Mc Croskey B. Value of Distal Colon Washout in Civilian Rectal Trauma-Reducing Gut Bacterial Translocation. The Journal of Trauma: Injury, Infection, and Critical Care. 1988;28(7):989-994.

[17]. Burch J, Feliciano D, Mattox K. Colostomy and Drainage for Civilian Rectal Injuries. Annals of Surgery. 1989;209(5):600-611.

[18]. Bostick P, Johnson D, Heard J, Islas J, Sims E, Flemming $A$ et al. Management of Extraperitoneal Rectal Injuries. Journal of The National Medical Association. 1991;85(6):460-463.

[19]. Atkin W. Single blind, randomised trial of efficacy and acceptability of oral Picolax versus self administered phosphate enema in bowel preparation for flexible sigmoidoscopy screening Commentary: participants should have been told they were being randomised Commentary: opportunity for patient partnership was lost. BMJ. 2000;320(7248):1504-1509. 